\title{
Modelling of Laminar Diffusion Flames in Vitiated Environments
}

\author{
HEIMO TUOVINEN \\ Department of Fire Safety Engineering, Lund University \\ PO Box 118, 22100 LUND. Sweden
}

\begin{abstract}
A laminar flamelet model has been used to calculate chemistry of methane-air flamelets in vitiated and non-vitiated environments. Calculated results for temperature and stable species concentrations agree well with those obtained using other similar models. The present results also agree quite well with recent laboratory measurements on both laminar and turbulent diffusion flames. The largest discrepancies between measured and calculated results are for CO-concentrations.
\end{abstract}

KEYW ORDS: Flamelet model, Combustion models, Diffusion flames, Chemical kinetics

\section{INTRODUCTION}

About two thirds of deaths in fires are caused by $(\mathrm{CO})$ poisoning. The mechanism of formation of $\mathrm{CO}$ in fire is quite complicated and largely depends on fuel type, oxygen supply in surroundings, and how the fire develops, i.e. turbulence intensity.

To understand the formation of $\mathrm{CO}$ and other species in fires, one has to study the microstructure of flames. Ignition, combustion and extinction occur in a turbulent flame at the same instant in time. These phenomena can have spatial separations of only a few millimeters. Locally the mixture can be diluted by complete or incomplete products of combustion, whose temperatures can vary considerably. This influences the chemistry, and hence the combustion efficiency at that location. To predict combustion in diffusion flames, finite rate chemical kinetics must be modelled to take account of combustion efficiency, which varies considerably inside the same flame. This work [1] is concerned with diffusion flames under the influence of vitiation, i.e. fire gas recirculation, which always occurs in room fires. The modified version of Cranfield SNECKS-code (Solver for Non-Equilibrium Chemical-Kinetic Systems) is used to calculate the chemistry [2]. The model can be used with any flow field calculation model. 


\section{LAMINAR FLAMELET MODEL}

A laminar diffusion flame exhibits unique relationships for chemical species, temperature, enthalpy, viscosity, soot concentration, etc., in terms of mixture fraction (a conserved scalar). By assuming that a turbulent diffusion flame consists of microscopic elements that have the structure of an undisturbed laminar diffusion flame, these relationships can be averaged by using of an appropriate shape of the probability density function (PDF). It is assumed that the chemistry is fast and the chemical reactions occur mainly in these thin flamelets. These assumptions allow us to decouple the statistical uncertainties of a turbulent flow field from a complex multicomponent chemistry and make it possible to calculate the chemical kinetics and flow field separately. The calculated flamelets with different degrees of vitiation, strain rate (i.e. different turbulent intensity) etc., can be stored in a data library, from where they can be easily accessed during the flow field calculations.

A special numerical model of co-flowing laminar diffusion flame was used in the present study. This model was calculated using SNECKS [2]. The flame model is a modified version of the model used in Pratt's CREK code, which is described in ref [3]. SNECKS differs from CREK in that the stream-wise distance, $x$, in CREK is replaced by time in SNECKS. SNECKS is therefore a 1D unsteady code while CREK is a 2D steady code. Both codes use the non-dimensionalized stream function of Spalding as the cross-stream independent variable.

In such model flames, the thermally hypergolic ignition and combustion of co-flowing streams of methane and air is considered. The schematic of the flame is shown in fig. 1. Initial temperatures of $300 \mathrm{~K}$ in fuel oxidizer streams were used in non-vitiated cases. In vitiated cases, the air stream is diluted by combustion products (for simplicity assumed to consist of only $\mathrm{CO}_{2}$ and $\mathrm{H}_{2} \mathrm{O}$ ) at either $300 \mathrm{~K}$ (cold vitiation) or $1000 \mathrm{~K}$ (hot vitiation), so that the oxidizer stream temperature is dependent on the degree of vitiation. An initial temperature of $2000 \mathrm{~K}$ in the burning zone, the initially very thin sheet of stoichiometric proportions of fuel and oxidizer between the two co-flowing streams, was used to initiate combustion. The computationally efficient "expanding grid" was utilized, so that computational field occupies the entire shear layer as it grows wider downstream.

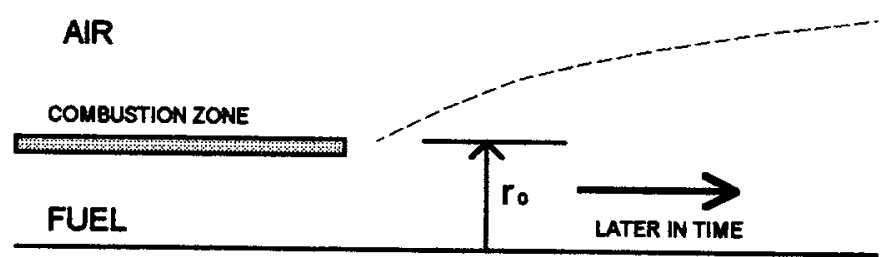

FIGURE 1. Axisy mmetric shear flow mixing and combustion of initially unmixed fuel and air. 
The governing set of differential equations for this special kind of diffusion flame consists of one-dimensional unsteady, parabolic differential equations of the form:

$$
\frac{\partial \phi}{\partial t}=\frac{\partial}{\partial \Psi}\left(\rho \Gamma_{\phi} \frac{\partial \phi}{\partial \Psi}\right)+\frac{S_{\phi}}{\rho}
$$

where $\phi$ is a symbol for any atomic element or enthalpy, $\Gamma_{\phi}$ is a transport coefficient, $S_{\phi}$ is the source term, and $\psi$ is a stream function.

The present chemical model for combustion of methane consists of 13 elementary reaction steps involving 11 species. The reaction scheme is shown in table 1.

TABLE 1. A 13-step reaction scheme for combustion of methane involving 11 species used in the present study. The reactions 1-12 are reversible (sign ' $=$ ') and reaction 13 , the fuel destruction reaction, is irreversible (sign ' - '). The parameters $A_{f}$ and $A_{b}$ denote Arrhenius preexponential factors $\left(\mathrm{cal} \mathrm{cm}^{3}\right)$ for forward and backward reactions, $\beta_{\mathrm{f}}$ and $\beta_{\mathrm{b}}$ temperature exponents and $E_{t}$ and $E_{0}$ activation energies (cal).

\begin{tabular}{|c|c|c|c|c|c|c|}
\hline & \multicolumn{3}{|c|}{ Forward rate } & \multicolumn{2}{|c|}{ Backward rate } & \\
\hline & $\bar{A}_{\mathrm{f}}$ & $\beta_{\mathrm{f}}$ & $E_{t}$ & $A_{b}$ & $\beta_{b}$ & $E_{\mathrm{b}}$ \\
\hline 1. $\mathrm{O}+\mathrm{H}_{2} \mathrm{O}=\mathrm{OH}+\mathrm{OH}$ & $1.76 \times 10^{10}$ & -0.02 & 16747.3 & $1.55 \times 10^{9}$ & 0.0 & 0.0 \\
\hline 2. $\mathrm{H}+\mathrm{H}=\mathrm{H}_{2}$ & $1.00 \times 10^{12}$ & -1.0 & 0.0 & $7.15 \times 10^{4}$ & -0.82 & 103328.3 \\
\hline 3. $\mathrm{O}+\mathrm{O}=\mathrm{O}_{2}$ & $6.00 \times 10^{2}$ & 0.0 & 0.0 & $5.83 \times 10^{10}$ & -1.0 & 1198367 \\
\hline 4. $\mathrm{H}+\mathrm{OH}=\mathrm{H}_{2} \mathrm{O}$ & $2.00 \times 10^{17}$ & -2.0 & 0.0 & $2.20 \times 10^{13}$ & 0.0 & 105217.9 \\
\hline 5. $\mathrm{H}+\mathrm{O}_{2}=\mathrm{OH}+\mathrm{O}$ & $2.00 \times 10^{11}$ & 0.0 & 16665.8 & $1.65 \times 10^{9}$ & 0.27 & 0.0 \\
\hline $6 \quad \mathrm{O}+\mathrm{H}_{2}=\mathrm{OH}+\mathrm{H}$ & $6.00 \times 10^{10}$ & 0.0 & 10008.6 & $1.94 \times 10^{10}$ & -0.03 & 8059.4 \\
\hline 7. $\mathrm{O}_{2}+\mathrm{H}=\mathrm{HO}_{2}$ & $1.50 \times 10^{9}$ & 0.0 & 994.5 & $2.10 \times 10^{12}$ & 0.0 & 46039.3 \\
\hline 8. $\mathrm{H}+\mathrm{HO}_{2}=\mathrm{OH}+\mathrm{OH}$ & $1.59 \times 10^{11}$ & 0.0 & 1080.0 & $1.26 \times 10^{10}$ & 0.0 & 39873.4 \\
\hline 9. $\mathrm{CO}+\mathrm{OH}=\mathrm{CO}_{2}+\mathrm{H}$ & $1.50 \times 10^{8}$ & 0.0 & 100.5 & $1.50 \times 10^{10}$ & 0.0 & 23519.9 \\
\hline 10. $\mathrm{H}_{2}+\mathrm{OH}=\mathrm{H}_{2} \mathrm{O}+\mathrm{H}$ & $1.50 \times 10^{10}$ & 0.0 & 5004.3 & $5.55 \times 10^{10}$ & -0.01 & 19802.4 \\
\hline 11. $\mathrm{CO}+\mathrm{O}=\mathrm{CO}_{2}$ & $6.00 \times 10^{7}$ & 0.0 & 0.0 & $1.31 \times 10^{10}$ & -0.58 & 125843.7 \\
\hline 12. $\mathrm{H}+\mathrm{O}=\mathrm{OH}$ & $3.00 \times 10^{8}$ & 0.0 & 0.0 & $6.96 \times 10^{10}$ & 0.21 & 101379.1 \\
\hline 13. $2 \mathrm{CH}_{4}+\mathrm{O}_{2}-2 \mathrm{CO}+4 \mathrm{H}_{2}$ & $1.75 \times 10^{7}$ & 1.0 & 24265 . & & & \\
\hline
\end{tabular}

The species transport properties are calculated from Chapman-Enskog expressions by using the Lennard-Jones parameters [2]. The Chapman-Enskog method is based on the three basic assumptions: a) molecular collisions are binary collisions, b) translational energy is treated using classical mechanics and c) spatial gradients of the microscopic or continuum properties of the gas are assumed to be small. These conditions are best satisfied by monoatomic molecules. The flames easily satisfy this requirement except at very high pressures. The method proceeds from a series expansion of the velocity distribution function about the Maxwellian distribution in order to obtain explicit expressions for the transport vector in terms of the gradients of the dependent variables of fluid dynamics from the Boltzmann equation [4]. The result is a set of Navier-Stokes equations, which is applicable for large deviations from the equilibrium.

For calculating heat capacities and enthalpies of species, the polynomial fit for temperature 
is used. The polynomial coefficients are stored in a data base. There are 14 coefficients for each species stored in the data base: seven coefficients for the temperarure range $300 \mathrm{~K}$ to $1000 \mathrm{~K}$ and seven for the temperarure range $1000 \mathrm{~K}$ to $5000 \mathrm{~K}$.

\section{RESULTS AND DISCUSSIONS}

In the present work, flamelet chemistry was calculated for methane-air laminar diffusion flames in both non-vitiated and vitiated atmospheres. The results have been compared with both laminar and turbulent diffusion flames in non-vitiated atmospheres. At the time this study was made, nothing could be found in the literature concerning flamelet problems in vitiated atmospheres.

Three degrees of vitiation were used: the oxidizer stream was diluted by $20 \%, 40 \%$ and $60 \%$ of combustion products. When using hot combustion products, the temperature of the mixture of combustion products + air was calculated as the arithmetic mean value of hot gas at 1000 $\mathrm{K}$ and air at $300 \mathrm{~K}$ (equal heat capacities for hot gas and air were assumed), which gives oxidizer stream temperatures $450 \mathrm{~K}, 570 \mathrm{~K}$ and $680 \mathrm{~K}$ for $20 \%, 40 \%$ and $60 \%$ vitiation, respectively.

Due to vitiation, the stoichiometric mixture fraction is shifted towards the lower values. By introducing a vitiation factor $\psi_{\text {vit }}$, the $\mathrm{O}_{2}$ mass fraction $Y_{\mathrm{O}_{2}, 2}$ in the oxidizer stream can be expressed as a function of $\psi_{\text {vit }}$ :

$$
Y_{O_{2,2}}=\frac{v_{O_{2}}^{\prime} M_{O_{2}}}{v_{O_{2}}^{\prime} M_{O_{2}}+v_{N_{2}}^{\prime} M_{N_{2}}}\left(1-\Psi_{v i t}\right) ; \quad 0 \leq \Psi_{v i t} \leq 1 ;
$$

where $M$ and $v$ are molecular weight and stoichiometric coefficient and indices $\mathrm{O}_{2}$ and $\mathrm{N}_{2}$ denote oxygen and nitrogen, respectively. The stoichiometric mixture fraction for a vitiated oxidizer stream can be calculated from a simple formula

$$
\xi_{s t, v i t} \approx\left(1+\frac{4}{Y_{O_{2}, 2}\left(\Psi_{v i t}\right)}\right)^{-1}
$$

The stoichiometric mixture fraction $\xi_{s t \text { it }}$ and the oxygen mass fraction $Y_{\mathrm{O}_{2,2}}$ in the oxidizer stream for $\psi_{\text {vit }}=0.00,0.20,0.40$ and 0.60 are shown in table 2 .

TABLE 2. Variation of stoichiometric mixture fraction and oxygen mass fraction with different degrees of vitiation.

\begin{tabular}{lllll} 
Vitiation factor & 0.00 & 0.20 & 0.40 & 0.60 \\
Oxygen mass fraction & 0.233 & 0.186 & 0.140 & 0.093 \\
Stoichiometric mixture fraction & 0.055 & 0.045 & 0.034 & 0.023 \\
\hline
\end{tabular}




\section{Comparisons with other studies}

\section{Comparison between theoretical models and Raman measurements}

The temperatures and major species concentrations calculated in the present study agree well with results from earlier calculations on laminar opposed jet methane-air flames by Peters and Kee [5]. Peters and Kee used the five scalar, four step, reduced mechanism, which is a systematically condensed form of an 18 elementary step reaction mechanism. The rate coefficients for resulting global reactions are combinations of species concentrations and unmodified elementary reaction rate coefficients. Thus, by using the reduced scheme, the concentrations of the intermediate species such as $\mathrm{OH}, \mathrm{O}$, etc. cannot be seen (but their effects are accounted for in calculations) as they can in the "full' scheme.

Figure 2 shows a comparison of the present calculations with those of Peters and Kee for strain rates of $450 \mathrm{~s}^{-1}, 300 \mathrm{~s}^{-1}$ and $100 \mathrm{~s}^{-1}$. Figure 2 also shows the scatter plot data from laser Raman experiments by Dibble et al. [6,7] on turbulent high-momentum methane jet flames, with a $41 \mathrm{~m} / \mathrm{s}$ central jet velocity, at the point $\mathrm{x} / \mathrm{D}=20$ and $\mathrm{r} / \mathrm{D}=1.14$ and 1.55 , where $\mathrm{x}$ and $r$ are the distances from burner top and the axis of symmetry, respectively, and $D$ is the burner exit diameter.
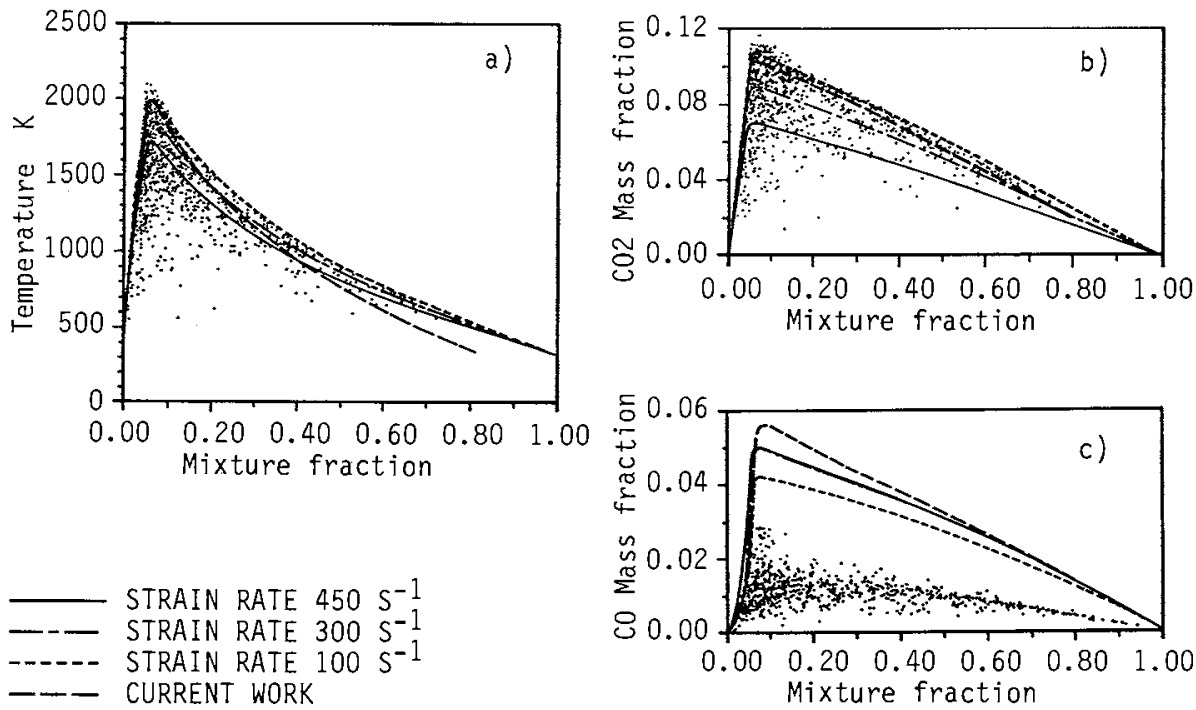

FIGURE 2. Joint pdf scatter plot for a) temperature, b) $\mathrm{CO}_{2}$ and c) $\mathrm{CO}$ versus mixture fraction. Lines denote calculations and dots denote Raman experiments [6]. 
Near stoichiometry, $\xi=\xi_{\text {st }}$, the temperatures predicted in the present study are quite near to those of Peters and Kee. For $\xi>0.4$ the temperature is about 100 to $150 \mathrm{~K}$ lower in the present study.

The concentration of $\mathrm{CO}_{2}$ at $\xi=\xi_{\text {st }}$ predicted by the present work is about the same as Peters and Kee's calculation for a strain rate of $100 \mathrm{~s}^{-1}$. For higher values of $\xi$, the $\mathrm{CO}_{2}$ concentration in the present study moves towards the $300 \mathrm{~s}^{-1}$ curve. This indicates that combustion is more incomplete for rich mixtures in the present model than in Peters and Kee's model. The concentration of $\mathrm{H}_{2} \mathrm{O}$ follows the same pattern as that of $\mathrm{CO}_{2}$ and comparisons with the present results are therefore omitted.

In the present study, somewhat higher concentrations of $\mathrm{CO}$ were found compared with Peters and Kee's calculations. There is a large discrepancy in $\mathrm{CO}$ concentrations between the calculated results and those measured with Raman methods. In the blue regions of hydrocarbon flames the laser signals are contaminated by fluoresence, the intensity of which is of the same order as the Raman signals. As the source molecules for this fluoresence are not fully known, this can lead to a large uncertainty in measured species concentrations. Discrepancies in CO concentrations between measured and calculated results can be attributed to this fluoresence.

\section{Comparison with measurements in laminar and turbulent diffusion flames in non-vitiated atm ospheres}

Smith and Cox [8] made detailed measurements of time-averaged concentrations of major species produced in different sizes (18 to $111 \mathrm{~kW}$ ) of turbulent diffusion flames of natural gas (94\% methane) on a $0.3 \times 0.3 \mathrm{~m}$ burner. All species measurements were time-averaged over a period of at least $10 \mathrm{~min}$. The curves show generally the same behaviour as the laminar diffusion flames measured by Mitchell et al. [9] and Tsuji and Yamaoka [10], except that the peak values of temperature and of $\mathrm{CO}$ and $\mathrm{CO}_{2}$ concentrations are shifted towards the higher mixture fraction values. As expected, the time averaging of the species fluctuations in the turbulent flames reduces peak values of concentrations.

Mitchell et al. [9] used a cylindrical diffusion flame burner consisting of two concentric tubes: an inner tube of radius $0.633 \mathrm{~cm}$ (fuel) and an outer tube of radius $2.54 \mathrm{~cm}$ (air). Tsuji and Yamaoka [10] used a rectangular combustion chamber with a cross section of $3 \times 12 \mathrm{~cm}$ and an uncooled porous (sintered bronze) cylinder, length $3 \mathrm{~cm}$ and diameter $6 \mathrm{~cm}$. Mitchell et al made radiation and conduction corrections to the thermocouple bead temperature to determine the unperturbed gas temperature at the bead location. The fact that Tsuji and Yamaoka did not make such a correction explains their lower peak values of measured temperatures, as can be seen in figure 3.

At $\xi=\xi_{\text {st }}$ the results from laminar flames obtained by Mitchell et al. yielded the same results for temperature and $\mathrm{CO}$ concentrations as computed using the present model. For $\xi>\xi_{\mathrm{st}}$, calculated values of temperature are about $200-300^{\circ} \mathrm{C}$ higher and $\mathrm{CO}$ concentration about 25 $40 \%$ higher. The temperatures measured by Tsuji and Yamaoka agree well with calculated results for $\xi>\xi_{\text {s: }}$. At stoichiometry, Tsuji and Yamaoka measured considerably lower values of temperature and $\mathrm{CO}$ and $\mathrm{CO}_{2}$ concentrations than Mitchell et al. For $\xi>0.2$ the temperatures measured by Tsuji and Yamaoka are higher than those calculated. The radiation 

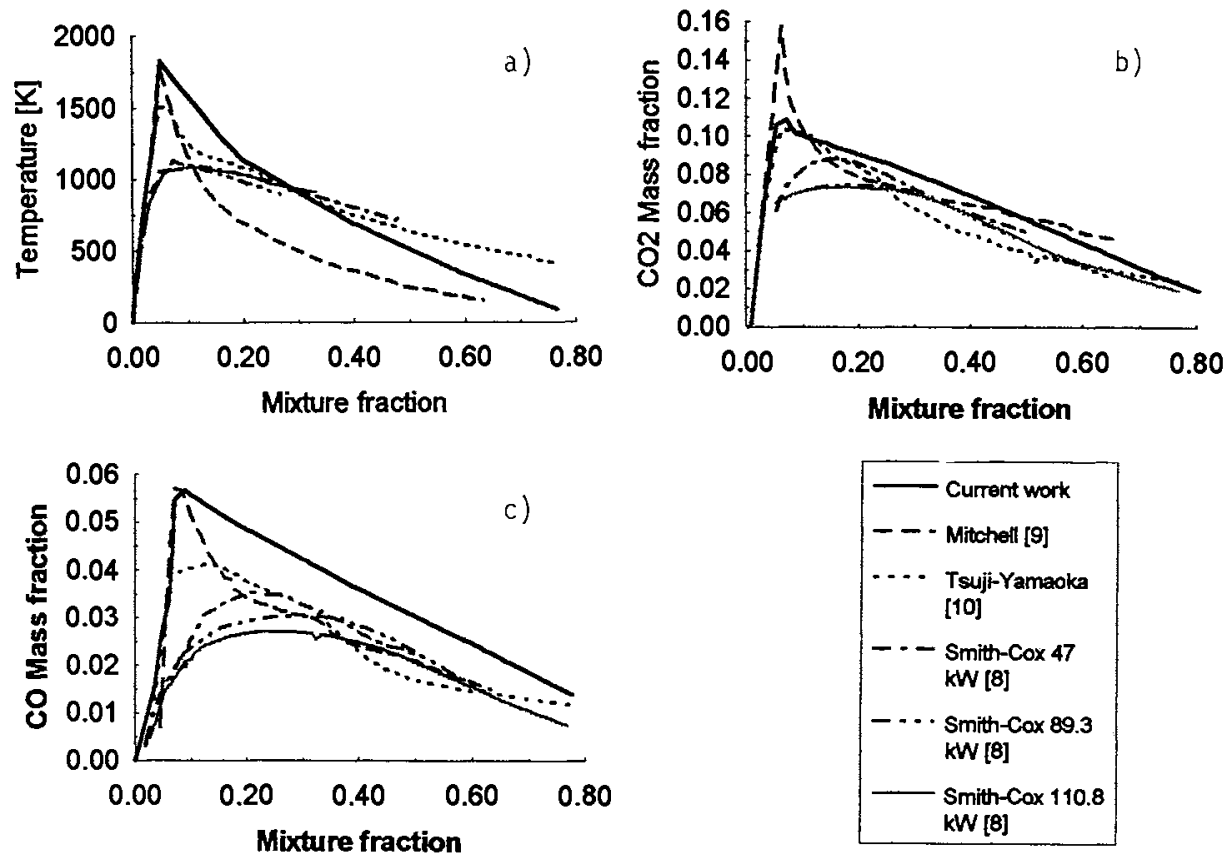

FIGURE 3. Comparison of current calculations with measured centreline mean temperarure (a) and mean mass fractions of $\mathrm{CO}_{2}$ and $\mathrm{CO}$ ( $\mathrm{b}$ and $\mathrm{c}$ ) as a function of mean mixture fraction. Mitchell et at and Tsuji and Yamaoka; laminar flames, Smith and Cox; turbulent flames.

energy losses are omitted in the present calculation model. These losses would shift the temperature to somewhat lower values and would increase the concentration of CO slightly.

The predicted mass fraction of $\mathrm{CO}_{2}$ at stoichiometry $(\xi=0.055)$ is about 0.10 , and the peak value is 0.11 at $\xi=0.06$. This is very close to Tsuji and Yamaoka's results on laminar diffusion flames. Mitchell et al., however, measured very high peak values of $\mathrm{CO}_{2}$ concentrations with a mass fraction of nearly 0.160 [9]. This value is even higher than the theoretical value (which should be about 0.150 ), if it is assumed that all carbon after combustion is in the form of $\mathrm{CO}_{2}$.

Most of the difference between values obtained from theoretical models (the present model and Peters and Kee's) and measured values can be attributed to carbon balance in combustion products. At stoichiometry, the calculated $\mathrm{CO}$ concentrations are about 3-4\%, having peak values at $\xi=0.10$ between 5 and $6 \%$, which are much higher than those measured. This large discrepancy may depend on the theoretical model. Maybe a more detailed chemical scheme is needed to calculate $\mathrm{CO}$ chemistry. On the other hand, it is difficult to measure $\mathrm{CO}$ concentration, due to its relatively low value and difficulties in determining the exact position of the stoichiometric mixture in the flame sheet. 


\section{Vitiated flamelets}

Fuel and stable species $\left(\mathrm{CO}_{2}, \mathrm{CO}, \mathrm{H}_{2} \mathrm{O}, \mathrm{O}_{2}\right)$ concentrations and temperatures are shown in figure 4. As expected, temperature decreases with increasing $\psi_{\text {vit. }}$ The peak temperature decreases approximately $100 \mathrm{~K}$ for every $10 \%$ increase of $\psi_{\text {vit }}$ in the case of hot gas vitiation, i.e. from about $2000 \mathrm{~K}$ for $\psi_{\text {vit }}=0$, to less than $1400 \mathrm{~K}$ for $\psi_{\text {vit }}=0.6$ (see fig. $4 \mathrm{e}$-f). When cold vitiating gas is used, the temperature decrease is slightly larger for a given increase in vitiation (fig 4 a-d).

In the case of hot vitiation, the peak value of $\mathrm{CO}$ mass fraction, $\mathrm{Y}_{\mathrm{Co}, \mathrm{top}}$, decreases from 0.056 to 0.035 with an increase in $\psi_{\text {vit }}$ from 0 to 0.6 . In the case of cold vitiation, $Y_{\mathrm{CO}, \text { top }}$ is almost constant. It should be noted that vitiation reduces the relative concentration of $\mathrm{O}_{2}$ in the oxidizer stream and hence a greater mass of oxidizer gas is needed for combustion of a certain portion of fuel. Since $\mathrm{CO}$ concentrations in fig. 4 are presented as a fraction of total mass in the mixture, $\mathrm{CO}$ production per unit of combusted fuel increases with increased vitiation. The precicted peak concentrations of $\mathrm{CO}$ per combusted amount of fuel increase by about 53\% for hot and by about $58 \%$ for cold vitiation when $\psi_{\text {vit }}$ is increased from 0 to 0.6 . The peak values of $\mathrm{CO}$ mass fractions and $\mathrm{CO} / \mathrm{CH}_{4}$ for different vitiations are shown in table 3 .

TABLE 3. Peak values $\mathrm{CO}$ mass fractions, $\mathrm{Y}_{\mathrm{CO}, \mathrm{top}}$, and $\mathrm{CO} / \mathrm{CH}_{4}$ at top concentration of $\mathrm{CO}$ for as a function of vitiation.

\begin{tabular}{|c|c|c|c|c|c|c|}
\hline$\psi_{\text {vit }}$ & \multicolumn{3}{|c|}{ Hot vitiation } & \multicolumn{3}{|c|}{ Cold vitiation } \\
\hline & $\mathrm{Y}_{\mathrm{CO} \text {,top }}$ & $\xi_{\text {top }}$ & $\mathrm{CO} / \mathrm{CH}_{4}$ & $Y_{\mathrm{CO}, \text { top }}$ & $\xi_{\text {top }}$ & ${\mathrm{CO} / \mathrm{CH}_{4}}_{4}$ \\
\hline 0.0 & 0.056 & 0.100 & 0.560 & 0.056 & 0.100 & 0.560 \\
\hline 0.2 & 0.050 & 0.086 & 0.588 & 0.058 & 0.089 & 0.652 \\
\hline 0.4 & 0.044 & 0.054 & 0.815 & 0.054 & 0.080 & 0.675 \\
\hline 0.6 & 0.035 & 0.041 & 0.854 & 0.052 & 0.059 & 0.886 \\
\hline
\end{tabular}

The $\mathrm{CO}_{2}$ concentration increases slightly with increased vitiation with hot gas, while remaining nearly constant for rich mixtures in the case of cold vitiation. The $\mathrm{H}_{2} \mathrm{O}$-concentration seems to be unaffected by whether the vitiation gas is cold or hot for the rich side of stoichiometry.

The mass fractions of $\mathrm{O}_{2}$ decrease from initial values in oxidizer streams at $\xi=0$ to zero at $\xi_{\text {st, vit }}$. The decrease is a linear function of $\xi$ for $\xi>\xi_{\text {st, vit }}$ at which the concentration of $\mathrm{O}_{2}$ is zero indicating that $\mathrm{O}_{2}$ is consumed totally.

The concentrations of $\mathrm{H}_{2}$ and the radicals $\mathrm{O}, \mathrm{H}, \mathrm{OH}$ and $\mathrm{HO}_{2}$ are presented in figure 5. The maximum $\mathrm{H}_{2}$ mass fractions occur at about the range $\xi=0.1$ to 0.2 . The temperature has a significant effect on $\mathrm{H}_{2}$ concentration. For hot gas vitiation at mixture fraction $\xi=0.1$ to 0.2 the mass fraction of $\mathrm{H}_{2}$ is 0.0035 for $\psi_{\text {vit }}=0.2$. For $\Psi_{\text {vit }}=0.6$, the $\mathrm{H}_{2}$ mass fraction is about 0.0027 . For cold vitiation, the $Y_{H_{2}}$ is about 0.0040 for all $\Psi_{\text {vit }}$. The peak value of $\mathrm{H}_{2}$ is also shifted slightly towards the richer mixture fraction values when the vitiating gas is cold.

O radicals exist only within a narrow band at the lean side of stoichiometry as a result of 

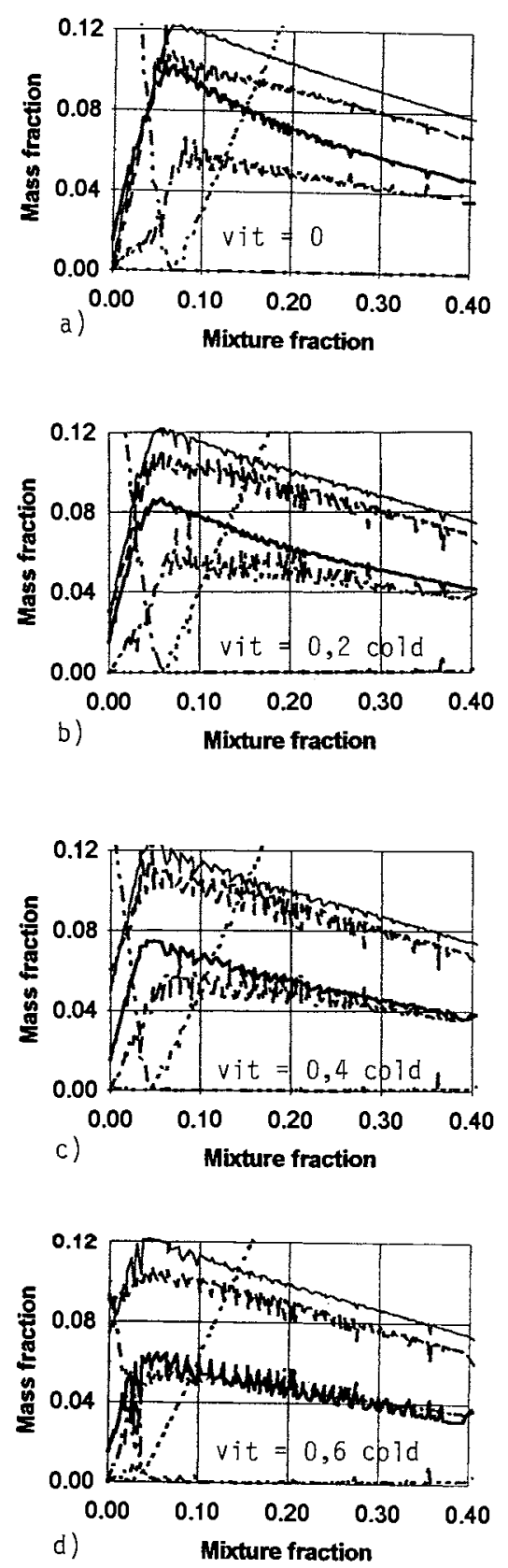
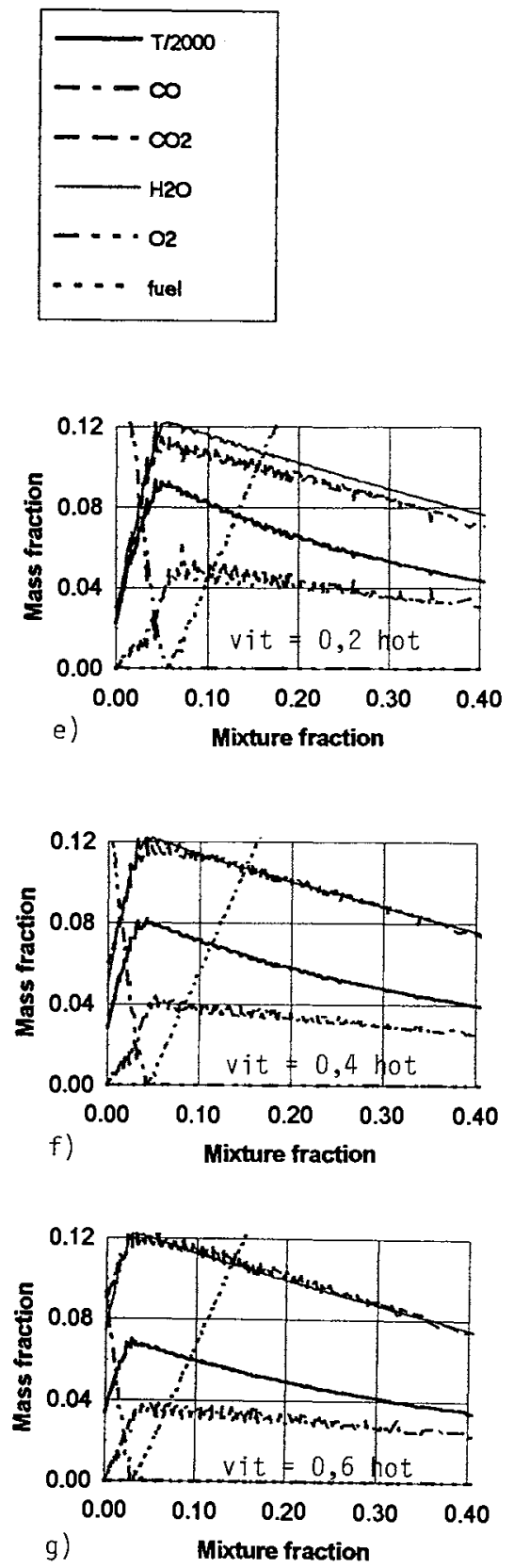

FIGURE 4. Temperature, $\mathrm{CO}, \mathrm{CO}_{2} \mathrm{H}_{2} \mathrm{O}, \mathrm{O}_{2}$ and fuel concentrations as a function of mixture fraction. 

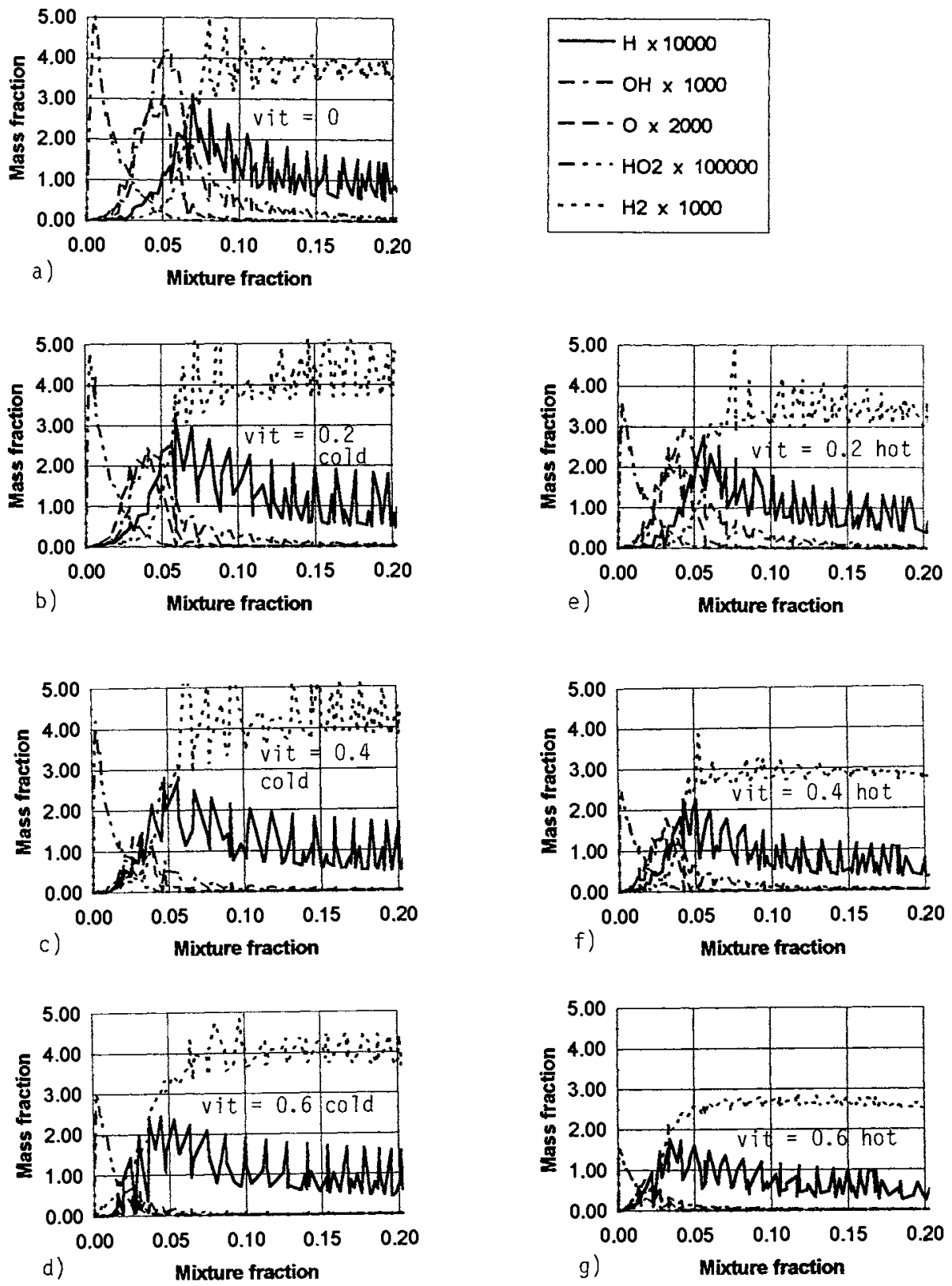

FIGURE 5. $\mathrm{H}, \mathrm{OH}, \mathrm{O}, \mathrm{HO}_{2}$ and $\mathrm{H}_{2}$ concentrations as a function of mixture fraction. 
dissociation of $\mathrm{O}_{2}$ due to heat from the flame. The peak values of $\mathrm{O}$ concentrations occur at $\xi \approx 0.95 \xi_{\text {st. }}$. The mass fraction of $O$ at that point is about 0.0015 for $\Psi_{\text {vit }}=0$ and 0.0004 for cold vitiation with $\psi_{\mathrm{vit}}=0.6$. At $\xi=\xi_{\mathrm{st}}\left(\xi=\xi_{\mathrm{st} \text {, vit }}\right.$ in vitiated cases) the $\mathrm{O}$ concentration has almost vanished. For hot vitiation, $O$ concentrations are somewhat lower than for cold vitiation.

As expected, the maximum concentrations of $\mathrm{H}$ radicals are located on the rich side of the stoichiometry, not far from the stoichiometric mixture in the flame sheet, where the temperature is high enough making methane molecules to loose their first $\mathrm{H}$-atoms.

$\mathrm{OH}$ radical concentrations in the flamelets follow the same pattern as $\mathrm{O}$ radical concentrations, except that the peak occurs at $\xi=\xi_{\text {st }}$. The peak concentration levels are about 2 to 3 times those of $\mathrm{O}$-radical levels. $\mathrm{OH}$ concentrations vanish at about $\xi=0.2$.

$\mathrm{HO}_{2}$ radicals exist only on the lean side of stoichiometry. The peak concentrations $\sim 1-5 \cdot 10^{-5}$ are located at the oxidizer boundary of flamelet $\xi \approx 0$. At the mixture fraction $\xi=\xi$ the $\mathrm{HO}_{2}$ concentration is zero.

\section{CONCLUSIONS}

The stable species concentrations and the temperatures calculated using the present thirteenstep reaction model agree well with the earlier calculations of Peters and Kee using a fourstep, reduced-reaction mechanism [5]. Near stoichiometry, agreement with recent measurements on laminar diffusion flames [9] is also quite good. The largest discrepancy was found for CO concentrations. For $\xi \geq 0.2$, the calculated $\mathrm{CO}$ concentrations are overestimated by $30 \%$.

The agreement of the present model with turbulent diffusion flames is also quite good [8], except that, due to time averaging, measured peak values of temperature and $\mathrm{CO}$ and $\mathrm{CO}_{2}$ concentration are considerably lower and occur further to the rich side of stoichiometry than values predicted by the model.

Vitiation affects the temperature and hence the chemistry. In the case of hot vitiation, the temperature is reduced approximately $100 \mathrm{~K}$ for every $10 \%$ increase in vitiation. In the case of cold vitiation, the temperature effect is larger. For hot vitiation, $\mathrm{CO}$ production is increased by $53 \%$ per combusted mole of methane when the vitiation factor is increased from 0 to 0.6 . For cold vitiation, the increase in $\mathrm{CO}$ is about $58 \%$.

\section{REFERENCES}

1. Tuovinen, H., Application of Flamelet Chemistry Model to Vitiated Methane-Air Diffusion Flames, Lund Institute of Technology, Department of Fire Safety Engineering, Lund, June 1992.

2. Liew, S.K.,"Flamelet Models of Turbulent Non-Premixed Combustion", PhD thesis. Department of Aeronatics and Astronautics, The University, Highfield, Southampton, UK. 
3. Pratt, D.T., "Calculation of Chemically Reacting Flows with Complex Chemstry", Studies in Convection, 2, Launder, B.E. (ed), Academic Press 1977).

4. Williams, F.A., Combustion Theory. Princeton University, The Benjamin/Cummings Publishing Company, Inc.

5. Peters, N., Kee, R.J., "The computation of stretched laminar methane-air diffusion flames using a reduced four-step mechanism", Combustion and Flame, 68, (1987).

6. Dibble, R.W., Masri, A.R., and Bilger, R.W. "The spontaneous Raman scattering technique applied to nonpremixed flames of methane", Combstion and Flame, 67,p 189.

7. Chen, J-Y., Kollmann, W., Dibble, R.W., Pdf Modelling of Turbulent Nonpremixed Methane Jet Flames. Combustion Research Facility, Sandia National Laboratories, Livermore, CA 94551, SAND89-8403 (1989).

8. Smith, D.A., Cox, G., "Major Chemical Species in Buoyant Turbulent Diffusion Flames", Combustion and Flame, 91, pp 226-238 (1992).

9. Mitchell, R.E., Sarofim, A.F., Clomburg, LA., "Experimental and Numerical Investigation of Confined Laminar Diffusion Flames", Combustion and Flame, 37, pp 227 $249(1980)$.

10. Tsuji, H, Yamaoka, I (1970), "Structure analysis of counterflow diffusion flames in the forward stagnation region of a porous cylinder", Thirteenth Symposium (International on Combustion, pp 723-731, Pittsburgh, Penn., Combustion Institute. 